\title{
The Effect of Tramadol Hydrochloride Intraarticular Injection on IL-6 Level in Patients with Tempromandibular Joint Internal Derangement
}

\author{
Yasser M. El-Gerby¹, Mohammed A. El-Sholkamy¹, Amal F. Abdelhai², Eman A. Elsharrawy ${ }^{1}$ \\ ${ }^{1}$ Faculty of Dentistry, Suez Canal University, \\ Ismailia, Egypt \\ ${ }^{2}$ Faculty of Medicine, Suez Canal University, \\ Ismaïlia, Egypt \\ Email: Yaserelgerby@yahoo.com
}

Received 2 August 2015; accepted 26 September 2015; published 29 September 2015

Copyright (C) 2015 by authors and Scientific Research Publishing Inc.

This work is licensed under the Creative Commons Attribution International License (CC BY). http://creativecommons.org/licenses/by/4.0/

(c) (i) Open Access

\section{Abstract}

Purpose: This study was conducted to detect IL-6 in synovial fluid in cases with TMJ internal derangement. Patients \& Methods: This study was conducted on forty patients ASA class I with TMJ Internal derangement. All patients had been subjected to arthrocentesis. The synovial fluid was collected before wash and lavage was done for the affected joint. Then, the selected patients were divided randomly into two equal groups, group I: consisted of 20 patients where arthrocentesis was performed for the affected joint followed by intraarticular injection of one $\mathrm{ml}$, tramadol hydrochloride. Group II: consisted of 20 patients where arthrocentesis was performed for the affected joint followed by intraarticular injection of one ml. sodium hyaluronate. Another synovial fluid sample was aspirated after one month. The interlieukin- 6 receptors in the aspirated synovial fluid were measured using humans IL-6 enzyme-linked immunosorbent assay. Results: IL-6 was detected in the synovial fluid of joints with internal derangement. During follow up assessment of IL-6, the maximum decrease in IL-6 level was in the patients of group I who subjected to arthrocentesis with tramadol injection, as the mean IL- 6 was $(4.93 \pm 1.36)$ followed by the patients of group II who subjected to arthrocentesis with sodium hyaluronate injection where the mean IL-6 level was $(6.88 \pm 1.76)$. There were significant $p$-value $=(P=0.000)$. Conclusions: It had been concluded that the detection of IL- 6 in the synovial fluid of joints with internal derangement considered an indicator for inflammatory reaction in the joint and also the efficacy of arthrocentesis with tramadol suggested its anti-inflammatory effect. 


\section{Keywords}

\section{Arthrocentesis, Sodium Hyaluronate, IL-6, Tramadol Hydrochloride}

\section{Introduction}

Anterior disc displacement of the TMJ is defined as a malrelationship of the disc to the condylar head and articular eminence. Although the disk may displace medially, laterally, or rarely posteriorly to the condyle, it generally displaces anteriorly [1].

Internal derangements can be divided into 2 categories: anterior disc displacement with reduction and anterior disc displacement without reduction. The condition in which the disc is located anteriorly and slips back into its normal position during opening of the mouth is called anterior disc displacement with reduction; the opposite condition is dubbed anterior disc displacement without reduction [1].

Internal derangements of the Temporomandibular Joint (TMJ) are characterized by displacement of the intra-articular disc, which acts as an obstacle to normal joint movement. It results in clicking and popping sounds or locking and an inability to open the mouth widely. These conditions may be associated with pain, especially during function, the most common causes are trauma or chronic parafuntion [2].

The traditional surgical manner in which internal derangement was treated involved either repositioning the disc (discoplasty) or, if this was not possible, removing the disc (discectomy) via an external approach [2].

A technique of irrigation of the upper compartment of the Temporomandibular Joint (TMJ) with Ringer's lactate solution to treat limited mouth opening due to internal derangement. They reported an increase in mouth opening and decrease of pain. This technique marked an evolution towards less surgical treatment [3].

The introduction of TMJ arthroscopy and later of TMJ arthrocentesis represented a major surgical advancement because it permitted a much less invasisve approach than an open operation for the management of these conditions [2].

A pilot study aimed to assess the safety and treatment of symptoms associated with internal derangement of the Temporomandibular Joint. There was a statistically significant reduction of pain intensity and joint sound in all patients. Repeated sodium hyaluronate injections' following arthrocenteses with Ringer's Lactate is an effective and safe method for the treatment of early stage reducing disc displacement of TMJ [4].

A limited absorption of the drug and that the mechanism of the analgesic effect of intraarticularly administered tramadol is not due to the systemic effects [5].

\section{Patients and Methods}

After approval of an ethical committee \& obtaining an informed concent of all patients, the study was conducted on forty patients who were divided randomly into two equal groups with chief complain of limited mouth opening, TMJ pain, and clicking sounds in the TMJ was included in this study. All patients included in the study were selected from the outpatient clinic of oral and maxillofacial department, Faculty of Dentistry, Suez Canal University.

Patients with history of degenerative joint disease, or those who have performed previous surgical treatment were excluded from this study.

\section{- The selected patients were subjected to the following assessment:}

\section{I-Preopertive assessment preparation:}

Complete medical and dental history was reported for every patient by using printed questionnaire sheet.

\section{A-Clinical evaluation:}

\section{A-1-Pain:}

All patients had a standard examination before surgery. They completed a visual analog scale (VAS) to assess pain with endpoints marked score 0 (no pain) and score 10 (worst pain ever experienced).

\section{A-2-Maximal mouth opening:}

The maximum interincisal mouth opening was measured preoperatively with a caliber to the nearest millimeter.

A-3-Clicking sounds:

Joint sounds were evaluated preoperatively by finger palpation and a stethoscope. 


\section{B-Radiographic evaluation:}

All patients were evaluated radiographically before the surgical procedures. The radiographic examination included panoramic view \& MRI. Figure 1

Based on these examination and patient's history, a diagnosis of TMJ internal derangement was made.

Group I: This group consists of 20 patients where arthrocentesis was performed for the affected joint followed by intraarticular injection of one $\mathrm{ml}$, commercially available tramadol.

Group II: This group consists of 20 patients where arthrocentesis was performed for the affected joint followed by intraarticular injection of one ml. commercially available sodium hyaluronate.

\section{Technique of Arthrocentesis \\ A-Preparation of the operative site:}

All patients were informed about the procedure, its possible complications, and about the materials used. The operative site was prepared aseptically using Betadine solution and the area was isolated with sterile drapes. The point of needle insertion was determined by drawing the canthal-tragus line and a point $10 \mathrm{~mm}$ in front of the tragus and $2 \mathrm{~mm}$ below the canthal-tragus line was marked. Another point $2 \mathrm{~mm}$ anterior to the former one was marked to serve as the point of insertion of the second needle used for collecting the synovial fluid aspirates.

For the auriculotemporal nerve block 0.3 to $0.5 \mathrm{ml}$ of an anesthetic solution was injected and then the needle was introduced into the upper joint compartment and approximately $3.5 \mathrm{ml}$ of anesthetic solution was injected.

\section{$B$-Collection of synovial fluid aspirate:}

The skin was penetrated with a 20-guage needle using an inferolateral approach, at a point $10 \mathrm{~mm}$ in front of the tragus and $2 \mathrm{~mm}$ below the canthal-tragus line and $2 \mathrm{~mL}$ of saline solution was injected. The patients were asked to open and close the mouth to mix the saline solution with the synovial fluid. The mixture of synovial fluid and saline was pumped; that is, it was aspirated and reinjected a total of 10 times, and then $1.89 \mathrm{~mL}$ on average (range, 1.2 to $2.2 \mathrm{~mL}$ ) was collected. Figure 2.

The synovial fluid aspirate was collected on sterile heparin tubes. All of the samples were immediately centrifuged at $3000 \mathrm{rpm}$ for 20 minutes to remove cells before storing the supernatant at $-70^{\circ} \mathrm{C}$ until assay.

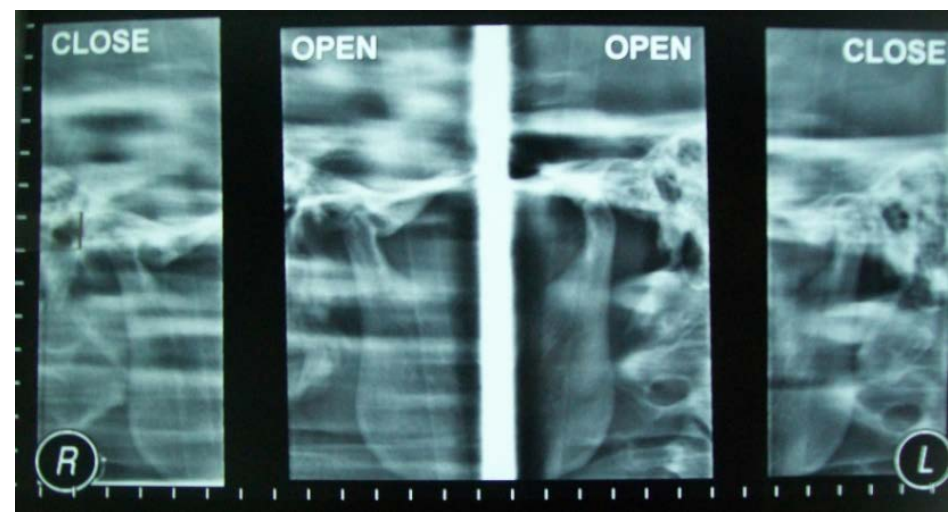

Figure 1. Digital X-ray of TMJ (close and open mouth): Right: TMJ with relatively limited movement of the joint (bony density is seen at posterior part of joint space) Left: TMJ shows normal radiographic appearance.

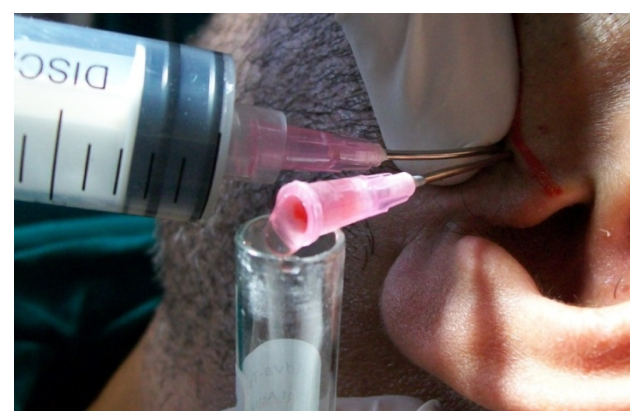

Figure 2. The synovial fluid aspirate was collected on sterile heparin tubes using $20 \mathrm{~cm}$ disposable syringe with 20-guage needle. 


\section{C-Operative technique:}

The TMJ was palpated and the upper joint space enlarged by downward and forward displacement of the mandible. Hydraulic pressure was created by injecting about $2 \mathrm{~mL}$ of saline solution into the space. A second 20-gauge needle was placed approximately $2 \mathrm{~mm}$ anterior to the former needle to establish outflow. The joint was then lavaged with $300-500 \mathrm{~mL}$ of saline solution injected into the upper joint compartment. The outflow needle was periodically occluded in order to create hydraulic pressure within the joint space, Figure 3.

On termination of the procedure, one $\mathrm{ml}$ of commercially available (Amadol ampoules I.M/I.V $100 \mathrm{mg} / 2 \mathrm{ml}$ ), produced by ADWAIA-EYGPT was injected in the joint of 20 patients represented group I., while in group II, one $\mathrm{ml}$ of commercially available sodium hyaluronate (curavisc $20 \mathrm{mg} / 2 \mathrm{ml}$ syringe) by IDT Biologika GmbH campany, Germany was injected, Figure 4 \& Figure 5.

After removal of both needles, the mandible was gently manipulated in order to evaluate joint movement.

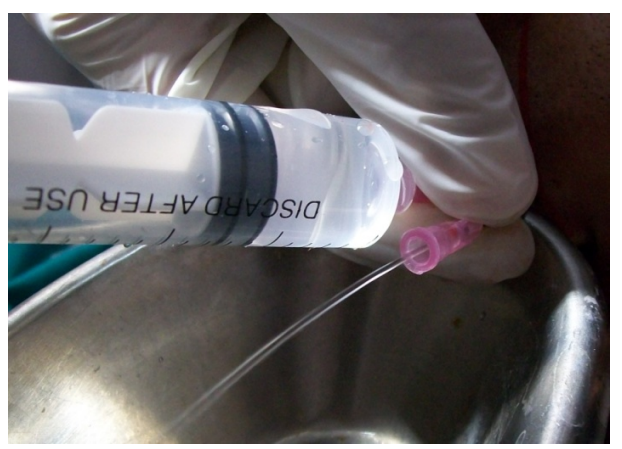

Figure 3. Outflow of the saline solution during the process of arthrocentesis using $20 \mathrm{~cm}$ disposable syringe with 20-guage needle.

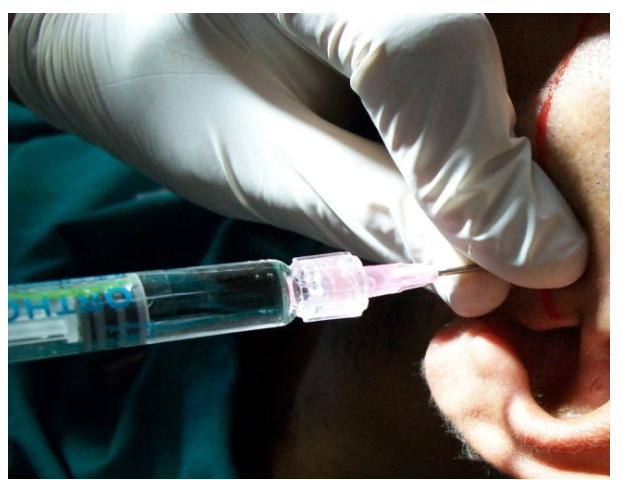

Figure 4. Injection of sodium hyaluronate in upper compartment of the joint which commercially available as (curavisc $20 \mathrm{mg} / 2 \mathrm{ml}$ syringe) by IDT Biologika GmbH company, Germany.

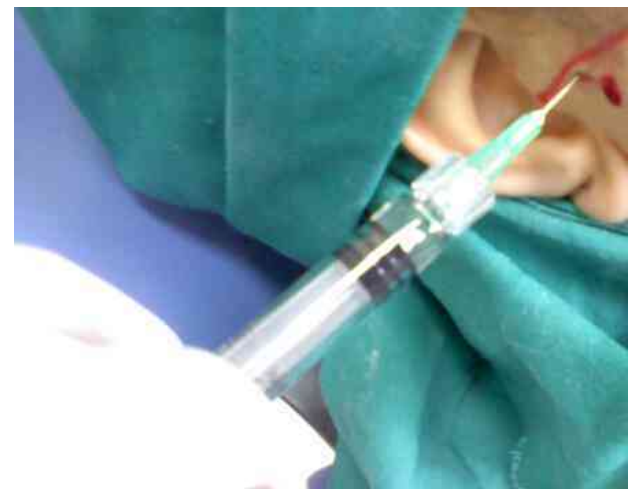

Figure 5. Injection of the tramadol into the upper joint compartment following the process of arthrocentesis. 
Finally, the patients practiced opening the mouth as wide as they could. After the arthrocentesis, they also were instructed for active and isometric opening exercises, protrusive, and lateral excursive exercises. Antibiotics were prescribed to be taken 3 times daily for 3 days.

Before arthrocentesis was performed, all patients had been subjected to withdrawal of synovial fluid from the affected joint and compared with sample that aspirated after one month. Then, interlieukin-6 receptors in the aspirated synovial fluid were measured using humans IL-6 enzyme-linked immunosorbent assay.

\section{Results}

IL-6 levels were significantly decreased in the two groups from preoperative to one month postoperative, as indicated in the Table 1.

\section{- Group I:}

There were high significant decrease in IL-6 level after one month as mean preoperative level was (mean $9.89 \pm$ 1.85) \& mean level after one month postoperative was (mean $4.93 \pm 1.36$ ) with the maximum change (mean $4.96 \pm 1.56)$ as $(\mathrm{P}=0.000)$. As shown in Table 1, Figure 6 .

\section{- Group II:}

As shown in Table 1, Figure 7, the mean of the preoperative IL-6 level was (mean $9.39 \pm 1.98$ ). While at one month postoperative, it decreased significantly to (mean $6.88 \pm 1.76$ ) with the maximum change (mean $2.50 \pm$ $0.81)$ as $(\mathrm{P}=0.000)$.

\section{- Comparison between both groups:}

IL-6 levels were significantly decreased in the two groups from preoperative to one month as indicated in Table 1 and Table 2 . There were no significant changes in the mean IL-6 level between the two study groups at the preoperative assessment .Table 2, Figure 8.

At the one month postoperative assessment of IL-6, the maximum decrease in IL-6 level was in the patients of group I who subjected to arthrocentesis with tramadol injection, as the mean of IL-6 was (4.93 \pm 1.36$)$ followed by the patients of group II who subjected to arthrocentesis with sodium hyaluronate injection, the mean of IL-6 level was $(6.88 \pm 1.76)$.

On comparing both groups together, there was high significant differences between group I and group II as $(\mathrm{P}=$ 0.000). Table 2, Figure 8.

Table 1. Changes in Interleukin-6 in the study groups.

\begin{tabular}{|c|c|c|c|c|c|c|}
\hline \multirow{2}{*}{\multicolumn{2}{|c|}{ Groups }} & \multirow{2}{*}{$\begin{array}{c}\text { IL-6 } \\
\text { Mean } \pm \text { SD }\end{array}$} & \multirow{2}{*}{$\begin{array}{c}\text { Paired Differences } \\
\text { Mean } \pm \text { SD }\end{array}$} & \multicolumn{3}{|c|}{ Paired T-test } \\
\hline & & & & $\mathbf{t}$ & P-Value & Sig \\
\hline \multirow{2}{*}{ Group I } & Before & $9.89 \pm 1.85$ & \multirow{2}{*}{$4.96 \pm 1.56$} & \multirow{2}{*}{14.24} & \multirow{2}{*}{0.00} & \multirow{2}{*}{ h.s } \\
\hline & After 1 month & $4.93 \pm 1.36$ & & & & \\
\hline \multirow{2}{*}{ Group II } & Before & $9.38 \pm 1.98$ & \multirow{2}{*}{$2.50 \pm 0.81$} & \multirow{2}{*}{13.85} & \multirow{2}{*}{0.00} & \multirow{2}{*}{ h.s } \\
\hline & After 1 month & $6.88 \pm 1.76$ & & & & \\
\hline
\end{tabular}

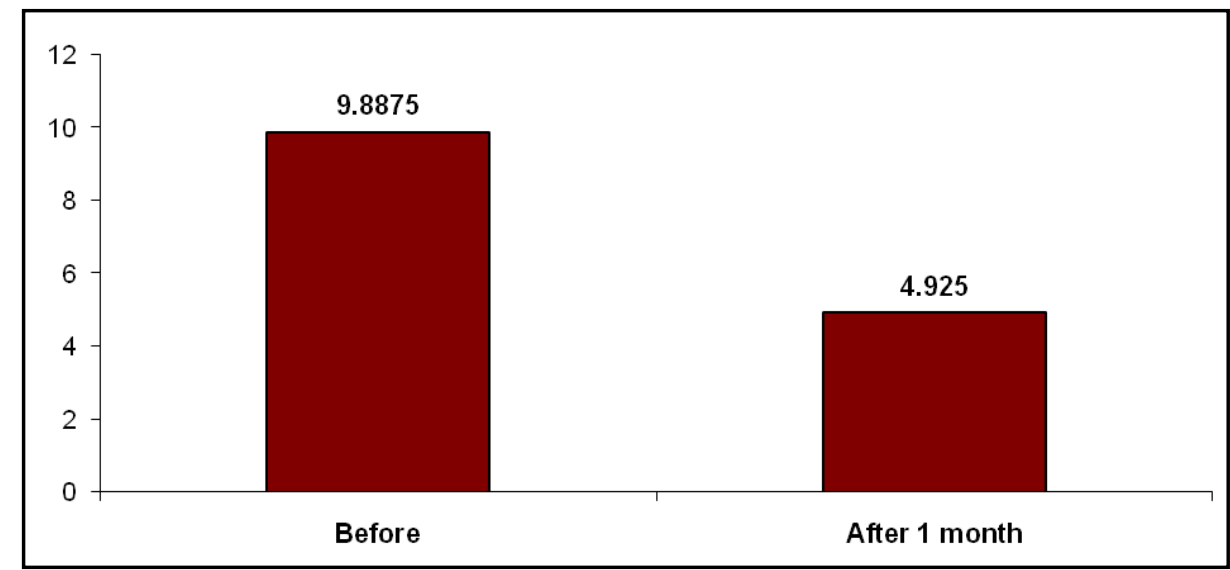

Figure 6. IL-6 for group I and changes along the study period SD: $4.96 \pm 1.56$. 
Table 2. changes in IL-6 level for the two study groups.

\begin{tabular}{|c|c|c|c|c|c|}
\hline \multirow{2}{*}{ IL-6 } & \multirow{2}{*}{$\begin{array}{c}\text { Group I } \\
\text { Mean } \pm \text { SD }\end{array}$} & \multirow{2}{*}{$\begin{array}{c}\text { Group II } \\
\text { Mean } \pm \text { SD }\end{array}$} & \multicolumn{3}{|c|}{ Independent T-test } \\
\hline & & & $\mathbf{t}$ & P-Value & Sig \\
\hline Before & $9.89 \pm 1.85$ & $9.38 \pm 1.98$ & 0.847 & 0.402 & n.s. \\
\hline After 1 month & $4.93 \pm 1.36$ & $6.88 \pm 1.76$ & -3.891 & 0.000 & h.s. \\
\hline
\end{tabular}

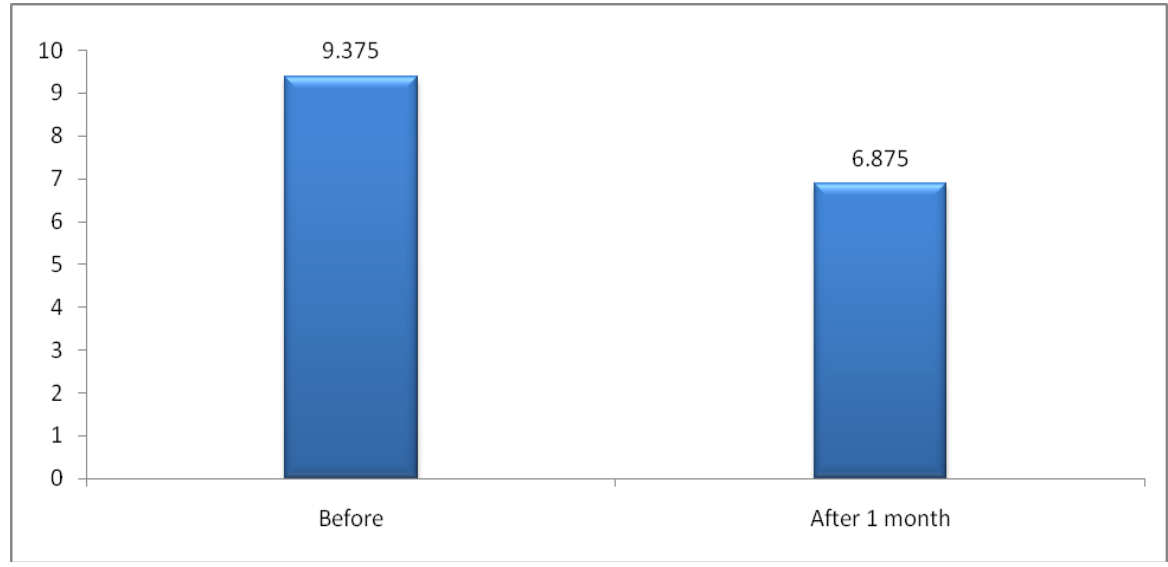

Figure 7. IL-6 for group II and changes along the study period SD: $2.50 \pm 0.81$.

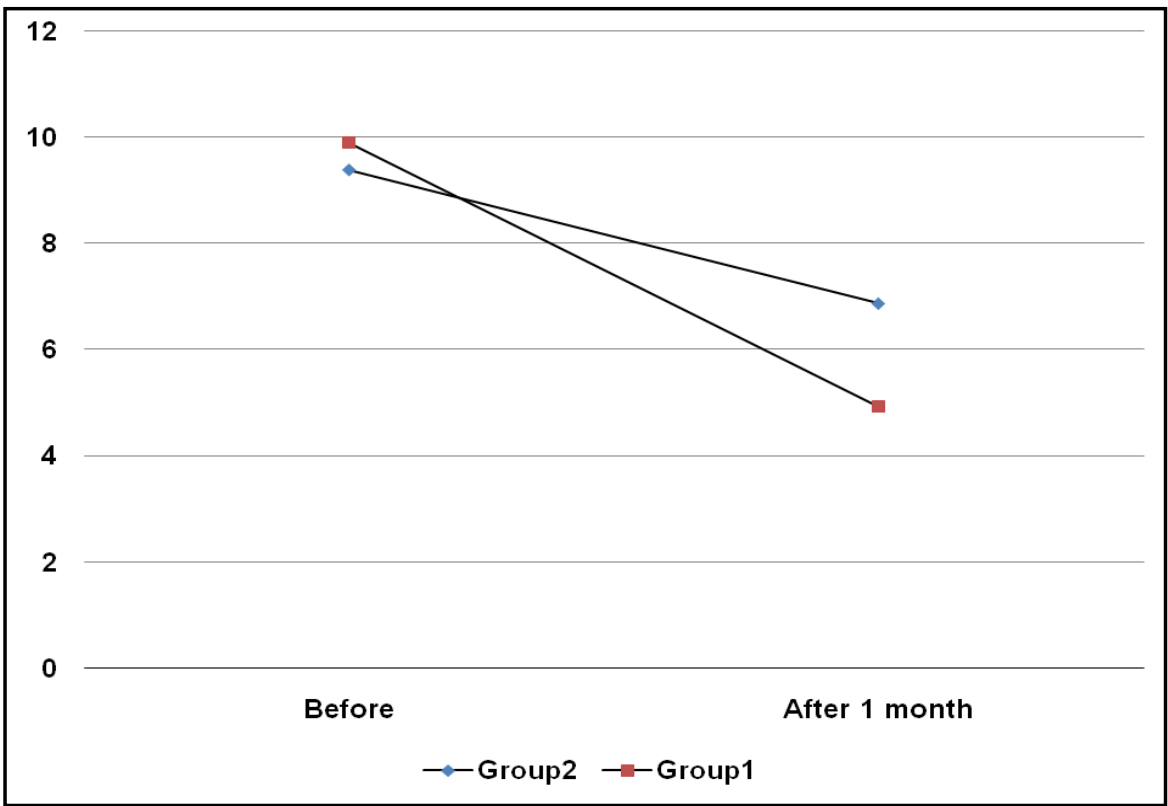

Figure 8. Changes in IL-6 level for the two study groups.

\section{Discussion}

IL-6 is a pleiotropic cytokine synthesized predominantly by monocytes, fibroblasts, and endothelial cells, although its secretion may also be found in T- and B-lymphocytes. Its production is triggered by IL-1, IL-2, and TNF- $\alpha$ but dampened by IL-4, IL-10, and IL-13. One of the most important effects of IL-6 is to induce the maturation of B lymphocytes into plasma cells and augment the immunoglobulin secretion. Other actions include the up-regulation of IL-2 and its receptor expression, stimulation of platelet production from megakaryocytes, differentiation of macrophage and osteoclast as well as the production of acute phase reactants [6].

IL-6 levels were significantly decreased in the two groups from preoperative to one month as indicated in the 
Table 1. There were no significant changes in the mean IL-6 level between study groups at the preoperative assessment while after one month postoperative assessment of IL-6, the maximum decrease in IL-6 level was in the patients of group I who subjected to arthrocentesis with tramadol injection, followed by the patients of group II who subjected to arthrocentesis with sodium hyaluronate injection. The ratio of IL-6 in unsuccessful cases of arthrocentesis was significantly higher than that in successful cases [7]. The concentrations of IL-6 and IL-11 in the joints with osseous changes in the condyle were significantly higher than in the joints without osseous changes of the condyle [8]. Also a superior result over COX-2 inhibitors \& intraarticular injection of tramadol was effective in management of clinical symptoms associated with internal derangements of the tempromandibular joint [9] and the patients with herniated intervertebral disks and carpal tunnel syndrome. Plasma level of IL-6 was decreased after treatment with tramadol [10].

\section{References}

[1] Larheim, T.A. (1995) Current Trends in Temporomandibular Joint Imaging. Oral Surgery, Oral Medicine, Oral Pathology, Oral Radiology, and Endodontology, 80, 555-576. http://dx.doi.org/10.1016/S1079-2104(05)80154-4

[2] Laskin, D.M. (2009) Arthrocentesis for the Treatment of Internal Derangements of the Temporomandibular Joint. Alpha Omegan, 102, 46-50. http://dx.doi.org/10.1016/j.aodf.2009.04.008

[3] Nitzan, D.W., Dolwick, M. and Martinez, G. (1991) Temporomandibular Joint Arthrocentesis: A Simplified Treatment for Sever Limited Mouth Opening. Journal of Oral and Maxillofacial Surgery, 48, 1163. http://dx.doi.org/10.1016/0278-2391(91)90409-F

[4] Tuncel, U. (2012) Repeated Sodium Hyaluronate Injections Following Multiple Arthrocentesis in the Treatment of Early Stage Reducing Disc Displacement of the Temporomandibular Joint: A Preliminary Report. Journal of Oral and Maxillofacial Surgery, 40, 685-689.

[5] Kapral, S., Gollmann, G., Walt, B., et al. (1999) Tramadol Added to Mepivacaine Prolongs the Duration of Axillary Plexus Blockage. Anesthesia \& Analgesia, 88, 853-856.

[6] Hiran T. (1998) IL-6 and Its Receptor. International Reviews of Immunology, 16, 249-284. http://dx.doi.org/10.3109/08830189809042997

[7] Nishimura, M., Segami, N., Kaneyama, K. and Suzuki, T. (2001) Prognostic Factors in Arthrocentesis of the Temporomandibular Joint: Evaluation of 100 Patients with Internal Derangement. Journal of Oral and Maxillofacial Surgery, 59, 874-877. http://dx.doi.org/10.1053/joms.2001.25019

[8] Kaneyama, K., Segami, N., Sato, J., Nishimura, M. and Yoshimura, H. (2003) Interleukin-6 Family of Cytokines as Biochemical Markers of Osseous Changes in the Temporomandibular Joint Disorders. British Journal of Oral and Maxillofacial Surgery, 42, 246-250. http://dx.doi.org/10.1016/S0266-4356(03)00258-4

[9] Tamer, A.H. (2012) Arthrocentesis with Injection of Tramadol and Cox-2 Inhibitor for the Management of Internal Derangements of the Tempromandibular Joint (A Comparative Study). Journal of American Science, 8, 66-72.

[10] Durval, C.K., Kimiko, S., Adriana, M.I., Olívia, B. and Rogério, S.J. (2009) Edgar Proinflammatory Cytokines in Patients with Neuropathic Pain Treated with Tramadol. Revista Brasileira de Anestesiologia, 59, 3. 